\title{
MODERNIZAÇÃO, ESTADO E POLÍTICAS TERRITORIAIS NAS METRÓPOLES LATINO-AMERICANAS
}

\author{
Amalia Inés Geraiges de Lemos \\ Profa. Dra. do Dep. de Geografia - USP
}

RESUMO: Pensar em modernizaçāo neste momento na América Latina nāo é só falar de mudanças tecnológicas e organizacionais. Modernizar tem um significado que atinge muito mais a idéia de desregulamentação e sobretudo privatizaçāo. Modernizar é o redimensionamento ou reforma do Estado. O trabalho desenvolve esse processo a nível das metrópoles latinoamericanas e as novas formas espaciais produzidas pelas exigências da política econômica neoliberal.

Palavras Chaves: modernizaçāo; formas espaciais

ABSTRACT: Modernization, at this moment, in Latin America, doesn't mean only technical and organizational changes. Modernization means changing rules and lessening state economic participation. To modernize means redimensioning or reforming the state. This article discusses this process at the level of latin american metropolis and the new spatial forms produced by the needs of neoliberal economical politics.

Key words: modernization, spatial forms

\section{ALGUNS CONCEITOS INICIAIS}

Todos os presidentes dos países da América Latina falam de modernizar o país. Que significado esses discursos têm?

Pensar em modernização neste momento na América Latina nāo é só falar de mudanças tecnológicas e organizacionais; modernizar tem um significado que atinge muito mais a idéia de desregulamentação e sobretudo privatização. Uma economia "moderna" é uma economia privatizada porque possui uma quantidade de adjetivos como eficiência, dinamismo, competitividade, racionalização, produtividade, etc.

Ante esta imposição econômica a América Latina deve fazer suas mudanças tecnológicas, sua política de exportação, sua nova divisāo do trabalho, a aplicação das políticas territoriais, a produçāo do seu espaço urbano e também agrário em função dos novos agentes da modernidade que são o capital privado nacional e transnacional. Uma questão séria é como convencê-los a investir nos países em crise.

Uma outra fase da modernizaçāo é o redimensionamento ou reforma do Estado. Diminuir o tamanho do Estado significa a privatização das empresas públicas. sejam agrícolas, de mineração, industriais, comerciais, financeiras, as de infraestrutura e os órgāos de prestação de serviços que estão a cargo do Estado. Esses processos de mudança no controle e na gestāo dos elementos materiais da produção, da distribuição e do consumo produzem grandes impactos a nível de estruturação espacial. As regiōes, as cidades, e também os conjuntos ou blocos de países têm que se reorganizar para responder às novas exigências do capital.

Essas relaçōes que o Estado sustenta com a sociedade e o território se concretizam especialmente no âmbito urbano no que diz respeito aos meios de consumo coletivo.

Os processos de urbanização acelerada que a América Latina sofreu, especialmente a partir da década dos 50 , mostraram pontos críticos que a ideologia da cultura urbana não conseguiu explicar nem muito menos resolver.

A formação das grandes periferias metropolitanas - formas espaciais de dominaçāo - trouxe a consciência da necessidade da intervenção do Estado para a resoluçāo dos problemas que se acumulavam. O Estado capitalista entáo entrava com formas de 
financiamento tanto no que diz respeito à infraestrutura como aos meios de consumo coletivo, possibilitando o desenvolvimento das condiçōes gerais da produção.

Assim, até a década dos 80 , o Estado se responsabilizou por alguns encargos que sustentaram a reproduçāo da força de trabalho e com a infraestrutura e criação de serviços que propiciavam a produção.

Com essa forma de gestão o Estado atendia também as necessidades de reprodução dos de menor ingresso o que, em última instância, redundava em vantagens ao capital. As políticas urbanas espaciais desse momento eram as mais claras expressōes da distribuição segregada dos meios coletivos de consumo.

$\mathrm{Na}$ década dos 80 as mudanças começavam a se produzir a passos acelerados de um processo que já tinha suas raízes em fins dos anos 70.

A nível mundial o capitalismo começa a tecer novas relaçōes nas quais as condiçōes de crescer implicavam novas modalidades de negociar a dívida externa, em especial com os maiores devedores, que são todos países da América Latina - dos preços das matérias primas à redefiniçāo do papel dos estados nacionais com a formação dos blocos político-econômicos.

Nos países da América Latina essa problemática internacional converteu-se em eixo central dos governos democráticos - com um forte conteúdo ideológico - e os objetivos vitais de todos eles são:

- como negociar a dívida externa

- como entrar na modernizaçáo a partir do binômio "liberalizar-privatizar".

\section{AS NOVAS FORMAS ESPACIAIS DE PARTICIPAÇÃO DO ESTADO}

A redefinição das relaçōes EstadoSociedade atinge todas a formas das organizaçóes espaciais. Há uma exigência de novas políticas de gestāo do território como um todo - a nível nacional e regional - para permitir um novo modelo de acumulaçāo e de participaçāo na economia internacional. Há neces-sidade de planejar o regional, o agrário e o urbano.
As formas espaciais existentes responderam às necessidades históricas de estruturaçāo territorial, onde havia uma exigência de formação do mercado interno com grande proteção do Estado. O sistema propiciava a concentração territorial da economia, da população, da cultura, da política, formando as grandes áreas metropolitanas que significavam vantagens na maximizaçāo da acumulaçāo do capitalismo internacional.

A modernizaçāo e a diminuição do Estado têm como pedra fundamental, do ponto de vista territorial, alguns itens que nos dizem respeito, que sāo:

- Desconcentração territorial inter-regional e intra-urbana dos meios de produção. $O$ grande esvaziamento das metrópoles. O novo modelo de acumulação já náo tem necessidade de concentrar māo-de-obra em uma cidade central - México, Buenos Aires, São Paulo, Caracas etc. Agora a necessidade é de impulsionar melhores condiçōes nas cidades do interior ou "cidades médias", onde se localizam novas formas dinâmicas da economia: indústrias de alta tecnologia que precisam pouca máo de obra, mas altamente especializadas, montadoras de automóveis, máquinas e equipamentos em geral, atividades turísticas, agroindustriais com alta tecnologia. As metrópoles são reestruturadas para uma maior flexibilidade da gestāo do capital a partir dos grandes centros financeiros e das comunicaçōes a nível nacionale internacional. O espaço metropolitano é hoje um locus da centralizaçāo dos grandes centros empresariais e de decisão, possibilitando as mudanças e a mobilidade tanto da mão-de-obra especializada como dos meios de comunicaçāo e transporte - acelerando as informaçōes - como sustentação às cidades-chaves da nova forma de acumulação, sejam as cidades portos como as de fronteiras.

O crescimento dessas cidades do interior ou médias também é realizado a partir de uma concentração acelerada e reproduz os mesmos processos das grandes áreas metropolitanas: a segregaçāo espacial e as penúrias urbanas. São novas formas de concentração náo planificadas e muito menos integradas a uma organização regional que considere as condiçōes de vida da população de menor poder aquisitivo. 
Essa reestruturação do espaço metropolitano traz junto formas novas de intervençāo regional para criar outro conjunto complementar de expressāo territorial.

Nessa tarefa o capital assume as obras rentáveis do Estado e o espaço vai tomando as formas e o conteúdo que essa nova relaçāo trará para a sociedade. Aqui colocamos esse surto de privatização e autoestradas, linhas aéreas, comunicações, serviços de aeroportos e até dos serviços de previdência. Os melhores exemplos desse novo modelo se dão no Chile e no México.

- A privatização das empresas estatais traz no bojo uma redução da ação do Estado na concentração e descentralização territorial de infraestrutura e em geral no que diz respeito à reprodução da força de trabalho. Nas grandes áreas metropolitanas das cidades do México, Buenos Aires, São Paulo, Rio de Janeiro etc. há uma diminuição dos investimentos quase a nível total nas áreas de saúde como de educação, sem considerar as condiçōes de infraestrutura de transporte, água corrente e moradia pressionando para que se estenda a privatização. $O$ transporte urbano - principal nexo de uniáo dos trabalhadores com sua fonte de renda - foi entrando num desgaste progressivo de serviço que hoje é, junto ao problema da moradia, um grande entrave do poder municipal em qualquer das grandes cidades da América Latina.

- O efeito mais acelerado que as novas formas das políticas néo-liberais estão produzindo é a nível da força de trabalho.

A situaçāo de crise que se vive na década dos 80 vai acumulando um processo de desemprego-subemprego que aumenta no ano de 1990-1991 com a implantaçāo da "modernizaçāo" nas grandes metrópoles latino-americanas. $\mathrm{Na}$ grande Buenos Aires, com a desindustrialização e a informatização da economia perdem-se, durante os anos 80, ao redor de 100.000 empregos. A indústria portenha, em 1974 , possuía $41 \%$ da PEA; em 1988 só tem 29,9\%. Com a diminuição do aparelho estatal e a perda do emprego público, ficaram 127.000 pessoas na rua em novembro de 1990 (60\% dos funcionários públicos).

Em São Paulo, em março desse ano, informava-se que havia 1 milhão de desempregados. $O$ desemprego atinge todos os níveis de qualificação. Há uma deterioraçāo do mercado de trabalho tendendo a um aumento com o enxugamento do Estado. O SEADE (Fundaçāo Sistema Estadual de Análise de Dados) forneceu os seguintes dados:

- Empregados sem registro em 1990 - 9\%

- Autônomos - 22\%

Em março de 1991, 12,3\% da Grande São Paulo já eram sem registro.

O México, país pioneiro, como o Chile, na implantação das novas políticas econômicas, em 1990 possuía 8 milhóes de desempregados, dos quais mais de 1 milhão só na área metropolitana.

No Chile, na cidade de Santiago, surgiram novas formas de planejamento participante no âmbito do município, para poder absorver as pressōes sociais do desemprego, que atingiu $30 \%$ da PEA nos anos 80.

Em todos os países da América Latina nas áreas metropolitanas em especial - a grande paisagem que se vive hoje é o reino da chamada economia informal.

Para Milton Santos as formas geográficas - os espaços - em especial os urbanos têm, em seu conteúdo social, "formas-conteúdo", onde as mudanças têm um significado dado pelos movimentos e forças da sociedade em suas transformaçóes.

Esses espaços nas metrópoles latinoamericanas vão tomando faces diferenciadas, conseqüência da grande massa dos chamados "informais" e que a literatura econômica rotulou de diversas maneiras durante o processo de urbanizaçāo latino-americano.

$\mathrm{Na}$ década dos 70, A. Quijano os denominava integrantes do "pólo marginal" da economia; Paul Singer mostrava que o mercado interno possuía consumidores para esse "setor marginal" nāo participante da produtividade, tecnologia e de toda a lógica da produçāo do "setor hegemônico". Milton Santos os analisa como dois circuitos econômicos paralelos: os circuitos superior e inferior. Esses circuitos produzem espaços urbanos separados e também complementares. 
O "circuito inferior", a chamada economia invisível, submersa ou paralela, por se organizar fora dos controles fiscais, nāo só se vale de uma produção não capitalista, mas também da capitalista. Hoje, empurrada pela grande crise econômica, tem formas de distribuição e de consumo tāo inseridas no cotidiano das metrópoles que o escritor Josué Montello, falando sobre o Rio de Janeiro, escreve que a Avenida Nossa Senhora de Copacabana deveria mudar seu nome para "Camelôpolis", pelo aspecto que a domina.

Dentro desse "circuito inferior" da economia há uma parcela bastante considerável . especialmente na cidade do México, em Santiago, Vinha Del Mar, e agora também em São Paulo, Rio de Janeiro e outras cidades importantes brasileiras - uma porcentagem expressiva de pessoas que vendem produtos industriais de alta tecnologia - aparelhos eletro-eletrônicos - e que fogem às pressóes fiscais, incluindo os direitos trabalhistas, mediante a prática dos ambulantes; embora hoje Sáo Paulo apresente um certo ambulante que está usando o dinheiro ganho a partir do FGTS (Fundo de Garantia por Tempo de Serviço) recebido por ocasiāo do desemprego, capital com o qual comprou algumas mercadorias e as comercializa na rua, enquanto sonha com a possibilidade de algum dia conseguir instalar o seu negócio.

Esses ambulantes nem sempre têm autorizaçāo das prefeituras, mas hoje essas áreas são inclusive negociadas, "alugadas", dada a pressāo do desemprego, da qual já tratamos.

Uma outra situação que poderíamos descrever, aumentada atualmente, é a dos camelôs e marreteiros de todas as classes encontrados em todos os pontos de ônibus, trens, metrôs, hospitais e semáforos (no entroncamento das avenidas Rebouças e Brasil, na cidade de São Paulo, lutam pelo "espaço" 300 pessoas oferecendo seus produtos, inclusive animais de pequeno porte. $\mathrm{Na}$ cidade do México confrontam-se nas esquinas dos semáforos "artistas circenses"(comedores de fogo, equilibristas, prestidigitadores, palhaços, etc.).

Nesse setor de limites e classificaçōes indefinidos que permitem grande diversidade de agentes, podemos mencionar uma forma expressiva em Buenos Aires - que atinge mais a classe média especializada, produto da desindustrialização da área metropolitana; estamos nos referindo às oficinas de "fundo de quintal", que hoje produzem roupas, carros, conseqüência da diminuiçāo do poder aquisitivo da populaçāo, e onde proliferam máquinas de toda espécie.

Enfim, o engenho e a técnica estāo em funcionamento para para subsistir à implantação da "modernizaçāo" do País.

Quais as perspectivas para transformar essas metrópoles a partir das novas políticas territoriais?

Em primeiro lugar devemos mencionar que o Estado já não é mais protagônico, não está mais preocupado em sustentar as formas de produção que existiam até a década dos 80 . Hoje ele é alheio às necessidades sociais. O Estado, que deveria ser o regulador ou procurar atenuar as diferenciações sociais, está excluindo-se de qualquer tipo de organização ou política que redunde em novas formas de produção espacial.

Não há nenhuma programação de algum grande processo de produção que absorva esse contingente de população metropolitana que ficou desempregada, ou pelas transformaçóes tecnológicas introduzidas, ou pelas indústrias anacrônicas que fecharam. O mercado de trabalho está reduzido e o Estado não há criado novas políticas para a década dos 90 .

A sociedade civil está assumindo as situações em que o Estado deveria ser o principal órgāo coletivo. A nível de município estão acontecendo algumas mudanças - com pouquíssimos recursos - mas pressionadas pelos movimentos sociais que já nāo são só de pobres, mas também de classes médias que nāo querem perder o nível alcançado nos anos "felizes'do desenvolvimento latino-americano.

Finalmente, qual será a "forma-conteúdo" do espaço metropolitano dos anos 90 ?

Para responder citamos a "paisagem" que apresenta de São Paulo Milton Campanario e que estendemos a todas as cidades grandes, desde o México a Buenos Aires: “... A cidade de São Paulo passa a polarizar o que poderia ser denominado 
como 'campo aglomerativo', exercendo sua liderança a partir do que é mais apreciado ao novo paradigma 'técnico-industrial': recursos humanos altamente qualificados, indústrias limpas de alta tecnologia, serviços especializados de toda espécie, gestāo administrativa e financeira do capital, unificação das decisōes empresariais e novas formas de cooperação técnica-gerencial e social. Esta cidade prospectiva que gradualmente está se estabelecendo também vivenciará o surgimento de forças políticas capazes de superar - padrão excludente de crescimento que caracterizou a sociedade brasileira. Isto também já começa a acontecer".

A ética social desaparecida deverá ser ressuscitada e para isso confiamos no papel da sociedade civil.

\section{BIBLIOGRAFIA}

COBOS, Emilio P. e GARCIA, Cecilia C.: "Límites a la desconcentración territorial". In: CIUDADES, Red Nacional de Investigación Urbana, México, D.F., no 3 jul-set 1989, ps.314.

TOLEDO, Enrique G: "La modernización Economica". In: CIUDADES, Red Nacional de Investigación Urbana, México. D.F. jul-set 1989, ps 19-22.
NICOLAS, Daniel H.e LINDÓNE. Alicia: "Reforma del Estado y Políticas Territoriales". In CIUDADES, Red Nacional de Investigación Urbana D.F., no 9, enero-marzo 1991, pg.15-21.

SANTOS, Milton: A Urbanização Desigual, Petrópolis, Ed. Vozes, 1980

Ed. Nobel, 1985.

Espaço e Método, São Paulo,

CACCIAMALI, Maria Cristina. Informalização Recente do Mercado de Trabalho Brasileiro. (Trabalho para a Organização Mundial do Trabalho e Ministério do Trabalho do Brasil) Sāo Paulo, Secretaria de Emprego e Salário, nov. de 1989.

CALDEIRAS, Milton: Sāo Paulo, Crise e Mudança São Paulo, Secretaria do Município de São Paulo/Brasiliense, 1989.

ROFMAN, Alejandro: Palestra proferida no Instituto de Estudos Avançados, USP, Sāo Paulo, junho 1991.

CENTRO DE ESTUDIOS ECONOMICOS DEL SECTOR PRIVADO A.C.La Economia Subterránea em México, Ed. Diana, México, 1986. 